\title{
Methods For The Diagnosis of Acute Appendicitis In
}

\section{Pregnant Women}

\author{
Tolga Kalaycı ${ }^{*}$, Ümit Haluk İliklerden \\ Department of General Surgery, Van Yuzuncu Yil University Faculty of Medicine, Van, Turkey
}

\begin{abstract}
Acute appendicitis (AA) is the most common non-obstetric surgical pathology during pregnancy. It is difficult to diagnose because of physiological changes. In our study, we aimed to define factors which are helpful in the diagnosis of AA.

This study was started at Van Yuzuncu Yil University Faculty of Medicine Department of General Surgery. We collected the data retrospectively from the pregnant patients who underwent surgery between January 2013 and January 2018 with the diagnosis of AA. Demographic features, laboratory analyses, imaging modalities, intraoperative and postoperative pathologic findings were gathered. Final pathology was accepted as gold standard; the sensitivity and specifity of the investigated parameters were calculated.

From our study, the second trimester had been the most common surgery applied time ( $\mathrm{n}=30,49.2 \%$ ). Although leukocytosis is seen in most patients $(67.2 \%)$, there was no significant relationship between leukocytosis and AA.

51 cases $(83.6 \%)$ were suitable for AA form evaluation of operation material. In 33 cases (Alvarado score of 7 and above),

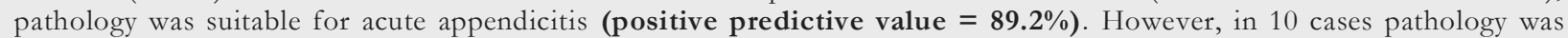
not suitable for AA (negative appendectomy rate was $16.4 \%$ ).

The most important result of our study is that; there is no valid diagnostic method in pregnant women for AA. We impress that the patient's history and physical examination is still the most important clinical parameter.
\end{abstract}

Key Words: Acute Appendicitis, Alvarado Score, Pregnancy, Ultrasound, Pathology.

\section{Introduction}

Acute appendicitis (AA) is a non-obstetric surgical pathology which is the most frequently seen during pregnancy. AA is seen in $0.1 \%$ to $0.2 \%$ of pregnant women. AA can be a life-threatening condition for both mother and fetus (1). Delayed diagnosis is correlated with fetal and maternal morbidity and mortality (2).

AA at pregnancy is challenging and is reported that $25-50 \%$ of patients had false diagnosis for several reasons (3). Diagnosis is particularly difficult during pregnancy, because of increasing uterine volume and the physiological leukocytosis. Therefore, early diagnosis and prompt surgical intervention are the most important approaches to avoid complications (4). It has been reported that any delay or misdiagnosis of AA will result in complicated appendicitis with peritonitis, which is correlated with early delivery, miscarriage, and fetus death (5).

A wide variety of tests are available at the time of diagnosis. Carefully taken anamnesis (pain characteristics, accompanying symptoms, history of surgery, etc.), physical examination, laboratory tests (leukocyte count, $\mathrm{C}$ - reactive protein (CRP) level and
Neutrophil/ Lymphocyte Rate (NLR)) and screening methods like ultrasonography are helpful. On the other hand, Alvarado score can be helpful at the time of diagnosis.

Every time physiological changes should not be ignored at pregnant women. The increased leukocyte count is not specific to the disease. At the time of diagnosis, ultrasound is the mostly used screening method. Also MRI is less used at the time of diagnosis if necessary. The absence of appendicitis by ultrasonography does not mean that the patient does not have acute appendicitis if physical examination is positive and does not exclude diagnosis. At this time short-range physical examinations, multidisciplinary approach (surgeons, radiologists etc.) is very important to prevent maternal / fetal mortality and morbidity. When the diagnosis is certain, appendectomy is suggested (laparotomically or laparoscopic). But diagnosis is not certain, diagnostic approaches (laparotomically or laparoscopic) should be considered.

In this study, we aimed to define factors which are helpful in diagnosis of AA in pregnant women. Thus, we are planning to prevent the death of mother and 
Table 1. Trimester status of patients and comparison results

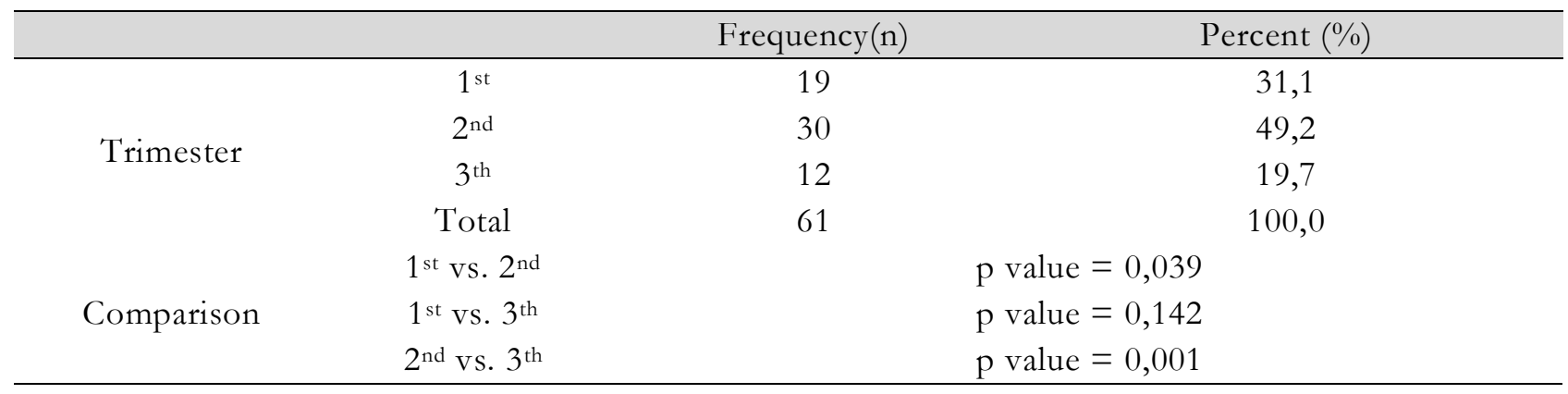

fetus by detecting earlier the cases of acute appendicitis.

\section{Material and Methods}

This study was started after obtaining permission from ethics committee in Van Yuzuncu Yil University. We collected the data retrospectively from the patients who underwent surgery between January 2013 and January 2018 with the diagnosis of AA during pregnancy.

Demographic features, imaging modalities, laboratory analysis, intraoperative and postoperative findings were gathered. At demographic features we questioned age of the patients (at the time of diagnosis for acute appendicitis) and trimester states. Leukocyte count (normal range from $4 * 10^{3}$ to $\left.11 * 10^{3}\right)$, C - reactive protein (CRP) level (normal range from $0 \mathrm{mg} / \mathrm{L}$ to $3 \mathrm{mg} / \mathrm{L}$ ) and Neutrophil/Lymphocyte Rate (NLR) were our parameters that we used. For all patients, Alvarado score was calculated and ultrasonography was used as an advanced imaging study. Unfortunately, MRI was not used in any patient.

Surgery methods (laparoscopy or laparotomy) and presence of perforation at the time of surgery were checked. Finally, the relationship between pathological diagnose and clinical parameters (trimester status, laboratory and ultrasonography findings) were evaluated.

Statistical Analysis: Final pathology was accepted as gold standard; the sensitivity and specificity of the investigated parameters were calculated. Descriptive statistics for the studied variables (characteristics) were presented as count and percent. Proportions of $\mathrm{AA}$ in pregnant women were compared with $\mathrm{Z}$ test for two proportions. Chi-square test was used for investigation of association between the two groups. The Pearson correlation coefficient was determined for each group to compare the associations between variables. Statistical significance levels were considered as 5\% and MINITAB for windows (ver.
13) statistical program was used for all statistical computations.

\section{Results}

The mean age of the patients who were evaluated at our study was 26.95 (17-50).

From our results, $2^{\text {nd }}$ trimester had been the most common surgery application time $(n=30,49.2 \%)$ among all cases. Besides, the $2^{\text {nd }}$ trimester was followed by $1^{\text {st }}$ trimester $(\mathrm{n}=19,31.1 \%)$ (Table 1$)$.

Leukocytosis was seen at 41 patients (67.2\%). Although leukocytosis was seen in more than half of the cases, there was no significant relationship between leukocytosis and AA $(\mathrm{p}=0.716)$.

In 37 cases $(60.7 \%)$ Alvarado score was equal or bigger than 7. Also, in 33 cases (Alvarado score 7 or above) pathology was suitable for acute appendicitis (positive predictive value $=89.2 \%$ ). Overall, the sensitivity of the Alvarado test was $64.7 \%$ and the specificity was $60 \%$.

In 33 cases, ultrasonography was suitable for AA $(54.1 \%)$. Mean appendix diameter was calculated as $8.8 \mathrm{~mm} \pm 2.2 \mathrm{~mm}$. Also, the presence of intraabdominal (especially paracolic or pelvic) collection in the ultrasound report was evaluated and in only 12 cases intra-abdominal collection was found $(19.7 \%)$.

While 42 cases were performed laparoscopically, 14 cases were performed laparotomically with Mc Burney incision. In 5 laparoscopic cases, because of difficult dissection the cases were finished laparotomically. In 14 cases (23\%) appendix perforation was seen.

From the pathology, 51 cases (83.6\%) were suitable for AA. On the other hand, in 10 cases were not suitable for AA. Our negative appendectomy rate was $16.4 \%$.

According to pathology, sensitivity and specificity of USG was $56.86 \%$ and $60 \%$, respectively. Also, there was a difference between the cases with appendicitis and non-appendicitis cases measured 
in USG and the preoperative CRP values ( $\mathrm{p}=$ 0.048 and 0.008 ). On the other hand, there was no significant difference in NLR median values between patients with and without appendicitis ( $p$ $=0.134)$. No relationship was observed between the trimester status and the pathology $(\mathrm{p}=0.780)$.

Acute appendicitis was detected in all 12 cases in whom abdominal fluid was detected in USG (positive predictive value $=100 \%$ ). The sensitivity and specificity of leukocytosis positivity were found to be $68.62 \%$ and $40.0 \%$, respectively.

\section{Discussion}

Acute appendicitis is the most frequently seen nonobstetric surgical disease during pregnancy (6). However, the incidence of AA is similar to that seen at non-pregnant women (7).

At most studies, occurrence of AA is reported during the $2^{\text {nd }}$ trimester like our study. On the other hand, Kim et al. showed that AA was seen in the $1^{\text {st }}$ trimester more frequently than other trimesters. Cho et al. found that AA was seen mostly in the $3^{\text {rd }}$ trimester. Finally Lee et al. found that there was no difference between trimesters (2).

Surgery method is also an important factor at AA during pregnancy. Most of surgeons use laparoscopic method. At the laparoscopic approach, there are many situations that we need attention. The appendix displaces to superolaterale due to fetus location. Other caution is that laparoscopy should be done in low insufflation pressure (under 10-12 mm Hg) and via open port method. Laparotomy should be performed if the duration of surgery is thought to be prolonged (8). Peled et al. compared laparoscopic appendectomies during pregnancy versus open ones. Laparoscopic surgery was performed in early pregnancy duo to the small size of uterus (9). At advanced gestational age, the surgeon might prefer open appendectomy due to uterine size in order to avoid unintentional harm to the uterus. Another explanation can be the non "anatomic position" of the appendix during advance pregnancy that may cause difficult in identifying and manipulating it while operating in pregnancy with enlarged uterus $(10,11)$. At our clinic, we usually perform laparoscopic appendectomy independent of trimester because of our clinical experience.

In AA, pain characteristic (which starts from the periumbilical area and settles in the lower right quadrant) is pathognomonic. At pregnant patients, signs and symptoms of AA may not be seen. In 1932, Baer et al. showed that appendix was shifted towards the right upper quadrant (12). Alvarado scoring system cannot be used in pregnant women because of physiologically nausea, vomiting and loss of appetite. Abdominal tenderness is most reliable diagnostic sign (2). When we evaluated patient's file, we found that physical examination findings were taken into consideration.

In pregnancy white blood cell (WBC) count is there about $12.000 / \mathrm{mm}^{3}$ which increases because of the pregnancy physiology. It may also be acceptable up to $30.000 / \mathrm{mm}^{3}$ during delivery. Kim et al. showed that WBC counts more than $16.000 / \mathrm{mm}^{3}$ should be correlated with perforation (2). Also, in the study of Akgül et al., Leukocytes and NLR were significantly different $(p=0.01)$ (13). In the study of Çinar et al.; WBC count, neutrophil count, mean NLR were significantly higher in appendicitis positive group compared to appendicitis negative group $(\mathrm{p}<0.001)$ (14).

In our study, the mean of Neutrophil/ Lymphocyte Rate $(\mathrm{NLR})$ was $6.89 \pm 3.9$. There was no significant difference in NLR median values between patients with and without appendicitis $(\mathrm{p}=0.134)$.

Alvarado score can be a predictive factor at AA patients during pregnancy. Despite this thought Tatl et al., showed that there was no significant difference when the Alvarado scores of both groups (pregnant and non-pregnant female) were compared $(p=0.947)(15)$. At our study, in 33 cases (Alvarado score of 7 and above), pathology was suitable for AA (positive predictive value $=89.2 \%$ ). Overall, the sensitivity of the Alvarado test was $64.7 \%$ and the specificity was $60 \%$.

Several studies have reported that the negative appendectomy rate is high in pregnant women and increases the risk of fetal loss and maternal mortality $(5,17)$. McGory et al. compared negative appendectomy rate between pregnant women and non-pregnant women and found that the rate was higher at pregnant women $(23 \%$ vs. $18 \%$; $<<0.05)$ (18). Ito et al. reported that the negative appendectomy rate in the pregnant group was significantly higher than in the non-pregnant group (36\% vs. $14 \%$; $<0.001)$ (19). In the studies of Aras et al. and Zingone et al., negative appendectomy rate was $15.8 \%$ and $17.4 \%$ in the pregnant group, respectively (20,21). Another study of Arer, reported that negative appendectomy rate as $30 \%$ (22). Negative appendectomy rate was mentioned as $23-50 \%$ in the literature for pregnant groups (18). In our case, negative appendectomy rate was $16.4 \%$ and lower than literature.

The most important result of our study is that; there is no valid diagnostic method in the diagnosis of $\mathrm{AA}$ 
in pregnant women and the patient's history and physical examination is still the most important clinical parameter at the time of diagnosis. If all laboratory and radiologic parameters are negative but physical examination is still suspicious, diagnostic surgical approaches (laparoscopy or laparotomy) should be done. We think that an experienced physical examination accompanied by a mentor/experienced clinician decreases negative appendectomy rates in pregnant appendicitis patients as in our clinic results.

Limitation of the study: One limitation of our study is that, retrospective design was based on analyses of patient records. The other limitation, unfortunately, our study was limited to a small sample group.

\section{Conflict of interest: None declared.}

\section{References}

1. Zhang Y, Zhao YY, Qiao J, Ye RH. Diagnosis of appendicitis during pregnancy and perinatal outcome in the late pregnancy. Chin Med J (Engl) 2009; 122: 521-524.

2. Jung SJ, Lee DK, Kim JH, Kong PS, Kim KH, Bae SW. Appendicitis during pregnancy: The clinical experience of a secondary hospital. J Korean Soc Coloproctol 2012; 28: 152-159.

3. Andersen B, Nielsen TF. Appendicitis in pregnancy: diagnosis, management and complications. Acta Obstet Gynecol Scand 1999; 78: 758-762.

4. Sachs A, Guglielminotti J, Miller R, Landau R, Smiley R, Li G. Risk factors and risk stratification for adverse obstetrical outcomes after appendectomy or cholecystectomy during pregnancy. JAMA Surg 2017; 152: 436-441.

5. McGory ML, Zingmond DS, Tillou A, Hiatt JR, Ko CY, Cryer HM. Negative appendectomy in pregnant women is associated with a substantial risk of fetal loss. J Am Col Surg 2007; 205: 534540.

6. Flexer SM, Tabib N, Peter MB. Suspected appendicitis in pregnancy. Surgeon 2014; 12: 82 86.

7. Chung JC, Cho GS, Shin EJ, Kim HC, Song OP. Clinical outcomes compared between laparoscopic and open appendectomy in pregnant women. Can J Surg 2013; 56: 341-346.

8. Burcu B, Ekinci Ö, Atak T, Orhun K, Eren TT, Alimoğlu O. Acute appendicitis in pregnancy: Case series and review. North Clin Istanbul 2016; 3: 60-63.

9. Peled Y, Hiersch L, Khalpari O, Wiznitzer A, Yogev Y, Pardo J. Appendectomy during pregnancy-is pregnancy outcome depending by operation technique? J Matern Fetal Neonatal Med 2014; 27: 365-367.

10. Carver TW, Antevil J, Egan JC, Brown CV. Appendectomy during early pregnancy: what is the preferred surgical approach? Am Surg 2005; 71: 809-812.

11. Walsh CA, Tang T, Walsh SR. Laparoscopic versus open appendicectomy in pregnancy: a systematic review. Int J Surg 2008; 6: 339-344.

12. Baer JL, Reis RA, Arens RA. Appendicitis in pregnancy. J Am Med Assoc 1932; 98: 1359-1364.

13. Akgül N, Gündeş E. Neutrophil / Lymphocyte Ratio in Acute Appendicitis: A State Hospital Experience. Turk J Colorectal Dis 2016; 26: 121 124.

14. Çınar H, Aygün A, Derebey M, Tarim İA, Akalın Ç, Büyükakincak S. et al. The significance of hemogram on diagnosis of acute appendicitis during pregnancy. Ulus Travma Acil Cerrahi Derg. Ahead of Print: UTD-62753 DOI: $10.5505 /$ tjtes.2018.62753.

15. Tatlı F, Yücel Y, Gozeneli O, Dirican A, Uzunköy A, Yalçın HC et al. The Alvarado Score is accurate in pregnancy: a retrospective casecontrol study. European Journal of Trauma and Emergency Surgery 2017; 11: 1-6.

16. Borushok K, JeffreyRB, Laing FC, Townsend RR. Sonographic diagnosis of perforation in patients with acute appendicitis. American Journal of Roentgenology 1990; 154: 275-278.

17. Aggenbach L, Zeeman GG, Cantineau AE, Gordijn SJ, Hofker HS. Impact of appendicitis during pregnancy: no delay in accurate diagnosis and treatment. Int J Surg 2015; 15: 84-89.

18. McGory ML, Zingmond DS, Tillou A, Hiatt JR, Ko JY, Cryer HM. Negative appendicectomy in pregnant women is associated with substantial risk of fetal loss. Journal of the American College of Surgeons 2007; 205: 534-540.

19. Ito $\mathrm{K}$, Ito $\mathrm{H}$, Whang $\mathrm{EE}$, Tavakkolizadeh A. Appendectomy in pregnancy: evaluation of the risks of a negative appendectomy. Am J Surg. 2012; 203: 145-150.

20. Aras A, Karaman E, Pekșen Ç, Kızıltan R, Kotan $\mathrm{MC}$. The diagnosis of acute appendicitis in pregnant versusnon-pregnant women: A comparative study. Rev AssocMed Bras 2016; 62: 622-627.

21. Zingone F, Sultan AA, Humes DJ, West J. Risk of acute appendicitis in and around pregnancy a population-based cohort study from England. Annals of Surgery 2015; 261(2): 332337.

22. Arer İ, Alemdaroğlu S, Yeșilağaç H, Yabanoğlu H. Acute appendicitis during pregnancy: case series of 20 pregnant women. Ulus Travma Acil Cerrahi Derg 2016; 22: 545-548. 